\title{
Retraction Note to: Self-Diagnosis of GFRP Composites Containing Carbon Powder and Fiber as Electrically Conductive Phases
}

\author{
Soon-Gi Shin ${ }^{1}$
}

Published online: 26 February 2018

(c) The Korean Institute of Metals and Materials 2018

\section{Retraction Note to: Metals and Materials International, Vol. 7, No. 6 (2001), pp. 605-611 https://doi.org/10.1007/BF03179259}

This article [1] has been retracted at the request of the Editor-in-Chief. Concerns were raised regarding substantial duplications with previous articles published in other journals in which S.-G. Shin is one of the co-authors. After a thorough analysis, we conclude that the concerns are valid. The article contains sections that substantially overlap with the following published article [2] (amongst others). S.-G. Shin has not responded to correspondence from the Editor about this retraction.
1. "Self-Diagnosis of GFRP Composites Containing Carbon Powder and Fiber as Electrically Conductive Phases" S.-G. Shin, Mat. Mater. Int., Vol. 7, Issue 6, pp. 605-611 (2001).

2. "Self-diagnosis function of FRP containing electrically conductive phase" Y. Okuhara, S.-G. Shin, H. Matsubara, H. Yanagida, and N. Takeda, Proc. SPIE 3986, Smart Structures and Materials 2000: Sensory Phenomena and Measurement Instrumentation for Smart Structures and Materials, p. 191, Society of Photo Optical, USA (2000).
The original article can be found online at https://doi.org/10.1007/BF03179259.

Soon-Gi Shin

ssg@kangwon.ac.kr

1 Division of Metallurgical and Materials, and Chemical Engineering, Dong-A University, 840 Hadan-2-dong, Saha-gu, Busan 604-714, Korea 